\title{
Overcoming data deficiency in reptiles
}

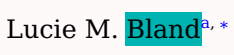

l.bland@unimelb.edu.au

Monika

${ }^{a}$ Centre of Excellence for Environmental Decisions, School of BioSciences, The University of Melbourne, Parkville 3010_ VIC, Australia

'bnstitute of Zoology, Zoological Society of London, Regent'-'s Park, London NW1 4RY, United Kingdom

${ }^{*}$ Corresponding author

\section{Abstract}

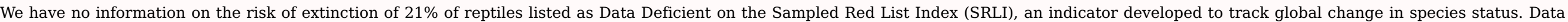

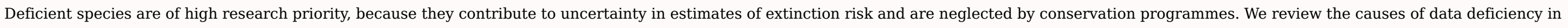

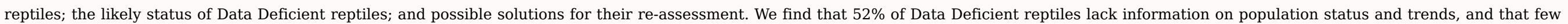

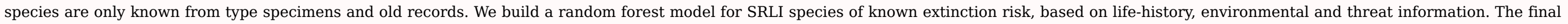

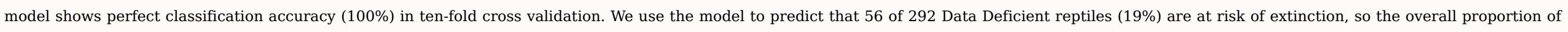

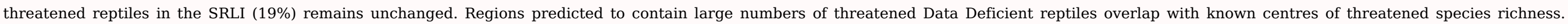

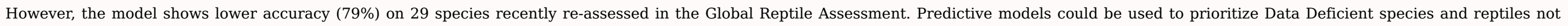
included in the SRLI, and new reptile assessments could be used to improve model predictions through adaptive learning.

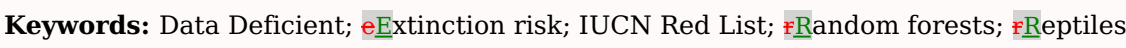

\subsection{Introduction}

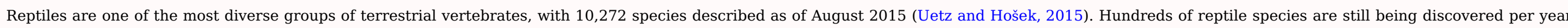

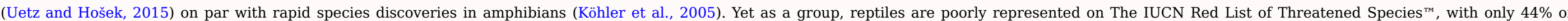

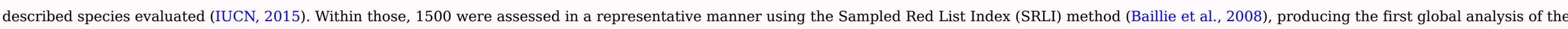

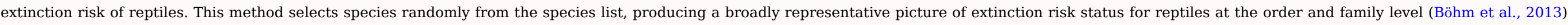
The analysis revealed that one in five reptile species is threatened with extinction, with risk highest among freshwater species and in tropical regions (Böhm et al., 2013).

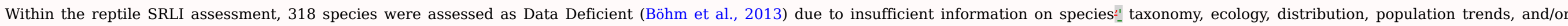

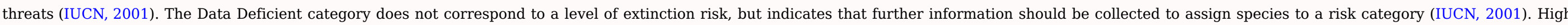

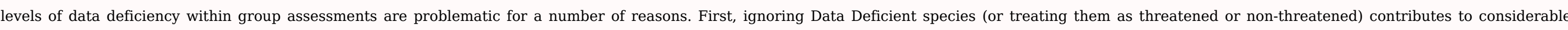

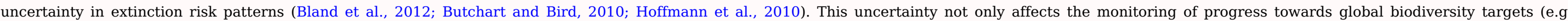

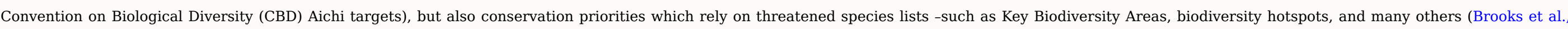

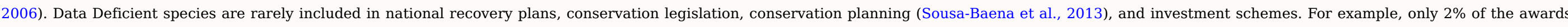

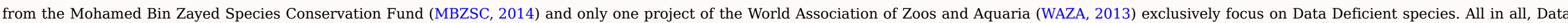
Deficient reptiles are offered very little protection and funding due to their uncertain extinction risk. 


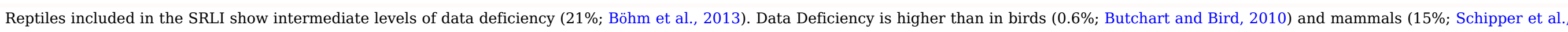

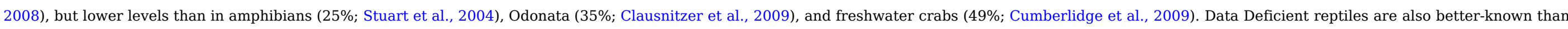

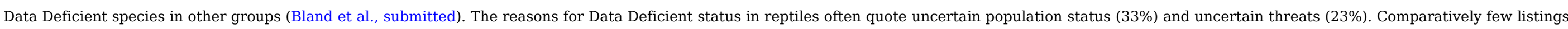

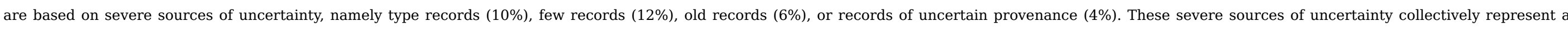

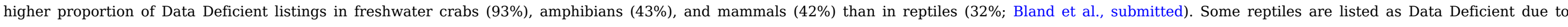

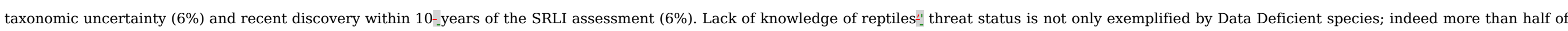
all known reptile species remain Not Evaluated (IUCN, 2015). Addressing data deficiency and broader data gaps are therefore key challenges for reptile assessments.

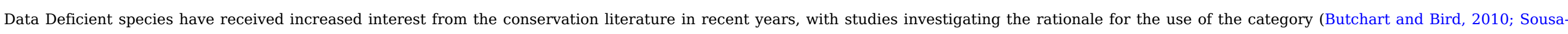

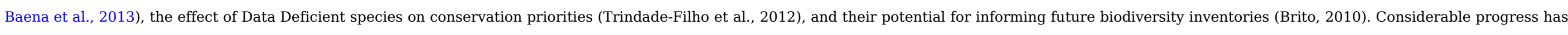

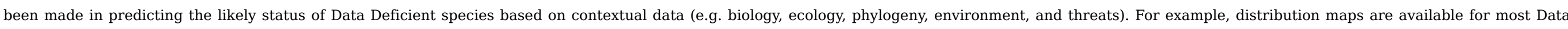

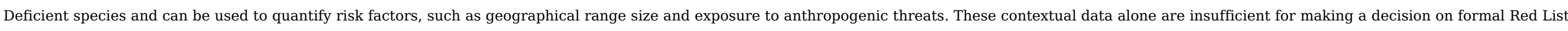

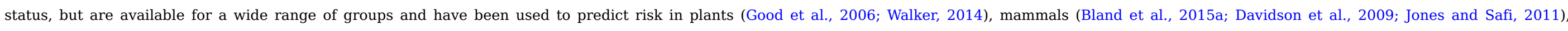

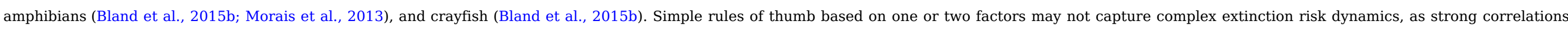

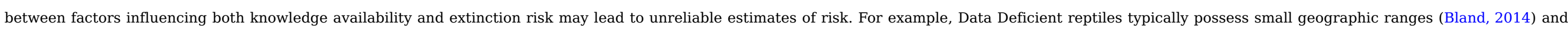

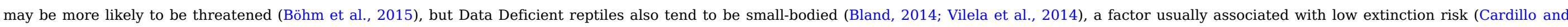
Meijaard, 2012). Predicting risk in Data Deficient must therefore rely on a wide variety of contextual data and robust modelling approaches.

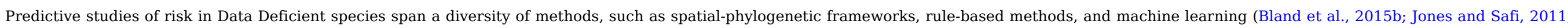

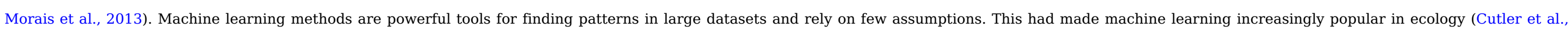

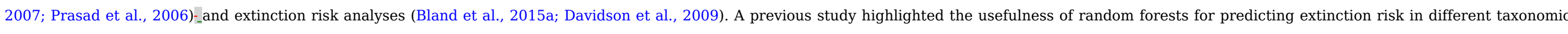

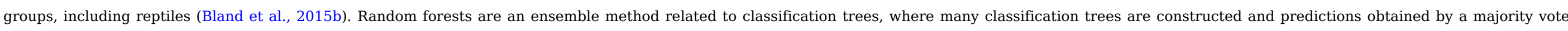

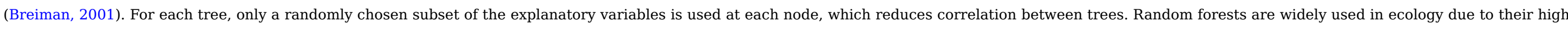

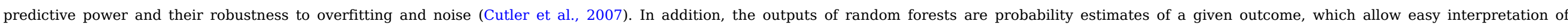
uncertainty when predicting complex processes such as extinction risk.

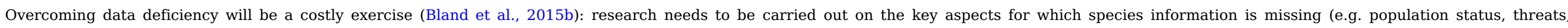

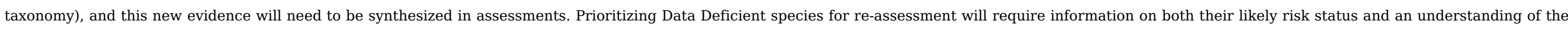

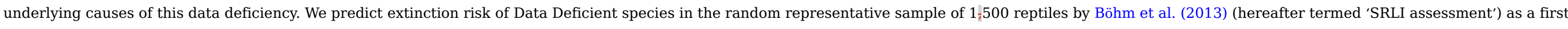

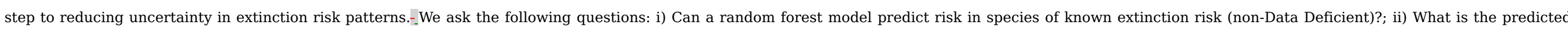
level of extinction risk faced by Data Deficient species?; and iii) How can our findings direct re-assessments?

\subsection{Methods}

\subsubsection{Dataset}

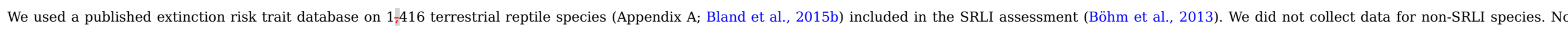

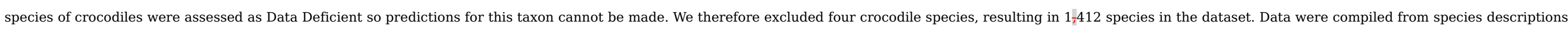

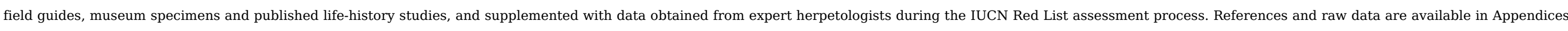

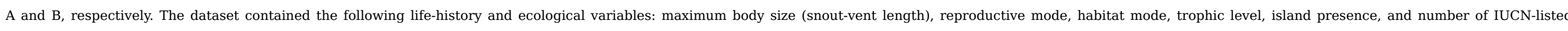

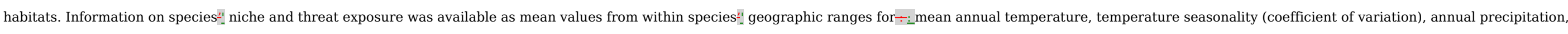

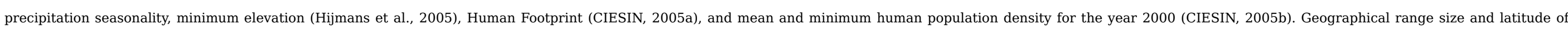




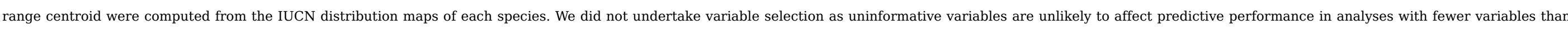

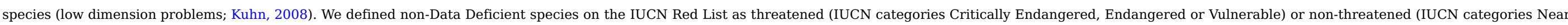
Threatened or Least Concern).

\subsubsection{Modelling}

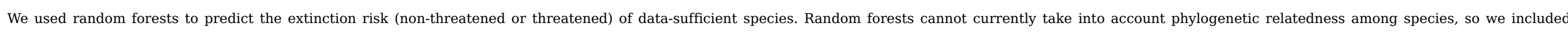

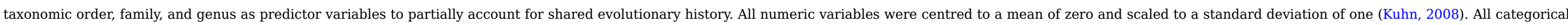

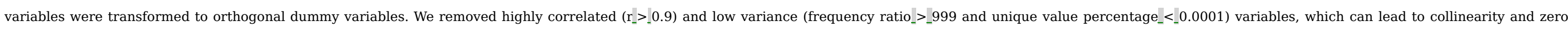

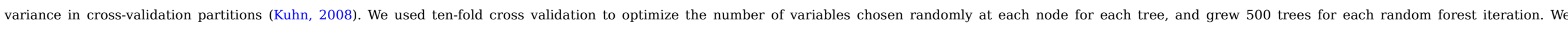

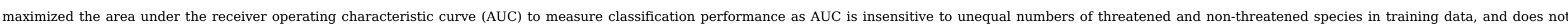

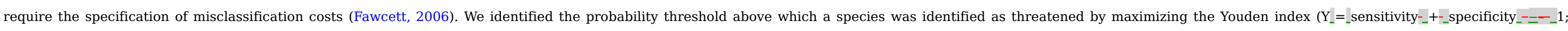

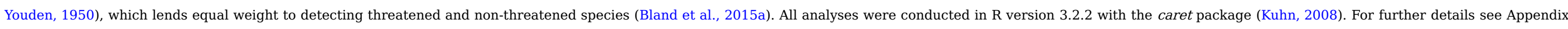
A.

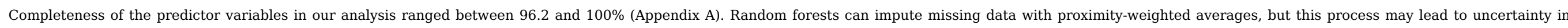

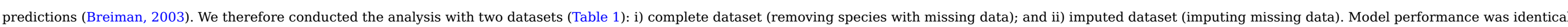
for the two datasets, so we used the imputed dataset for all further analyses to maximize sample size. Results for the complete dataset are reported in Appendix A.

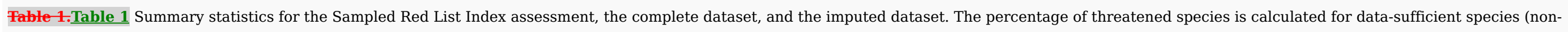
threatened-_+-_threatened).

\begin{tabular}{|c|c|c|c|}
\hline & SRLI assessment & Complete dataset & Imputed dataset \\
\hline Total species & 1473 & 1298 & 1412 \\
\hline Non-threatened species & 939 & 861 & 915 \\
\hline Threatened species & 223 & 172 & 205 \\
\hline Data Deficient species & 313 & 265 & 292 \\
\hline Percent threatened & 19.1 & 16.7 & 18.3 \\
\hline Percent Data Deficient & 21.2 & 20.4 & 20.7 \\
\hline
\end{tabular}

\subsubsection{Predictions for Data Deficient species}

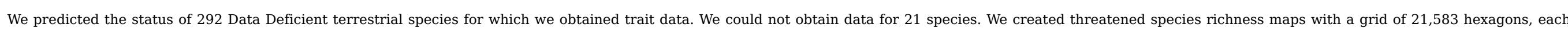

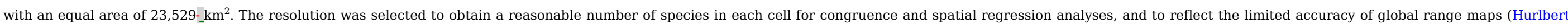
and Jetz, 2007).

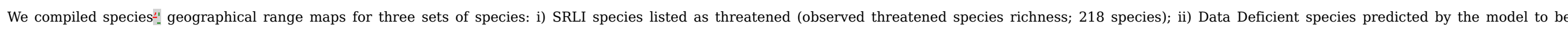

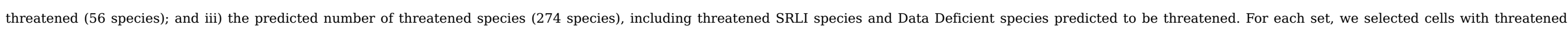

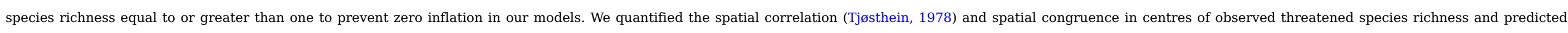

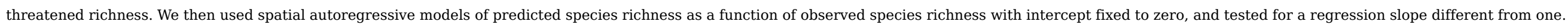




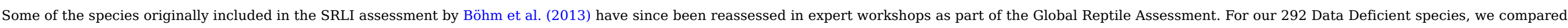

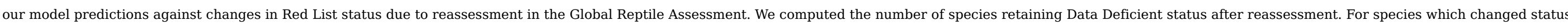
during reassessment, we investigated the congruence between predicted and reassessed status.

\section{3 Results}

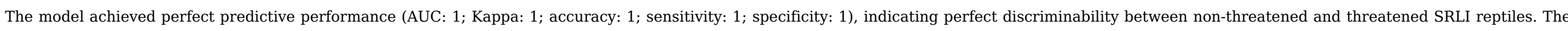

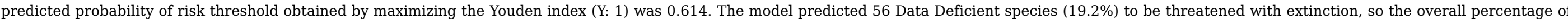

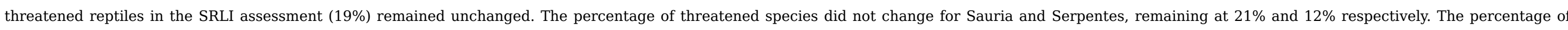

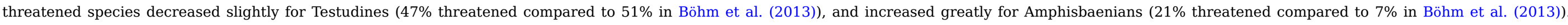

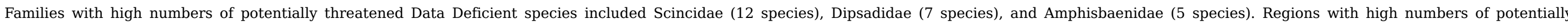

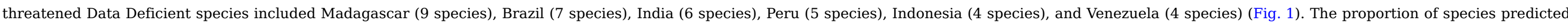
to be at risk varied among reasons for listing as Data Deficient (Fig. 2), which may reflect genuine differences in risk or uncertainty in contextual data.

A

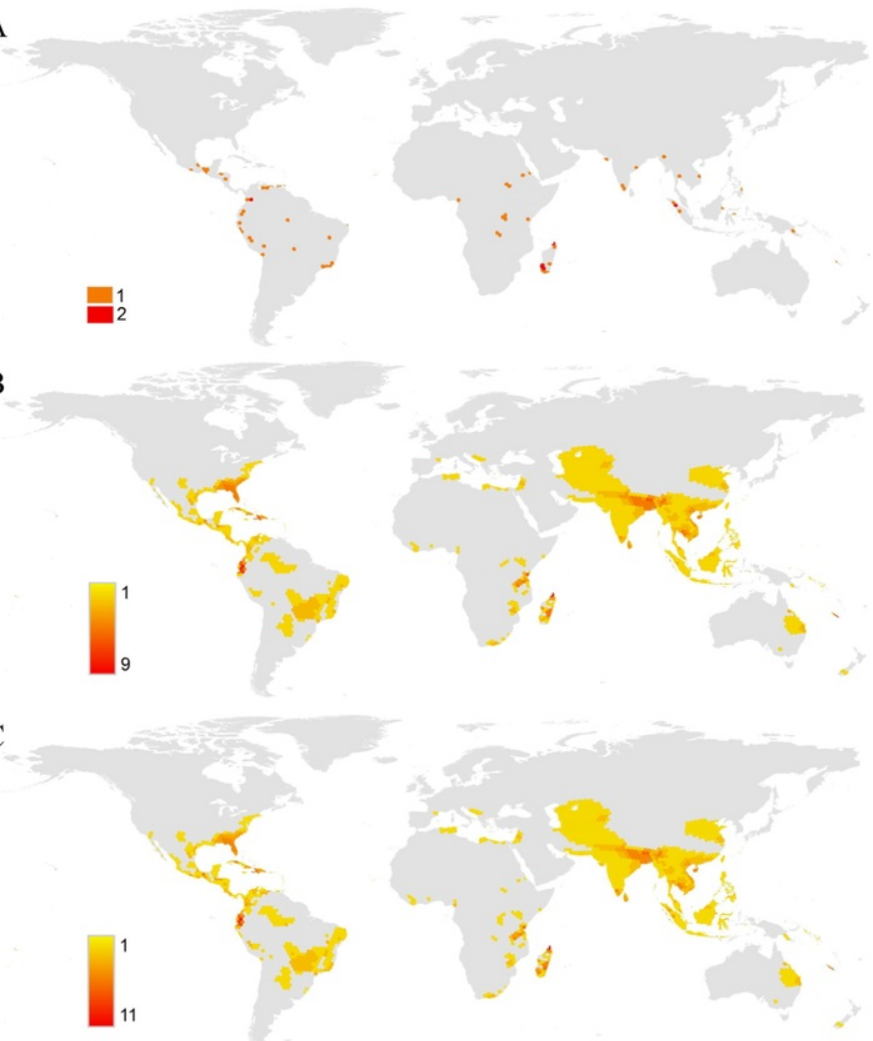

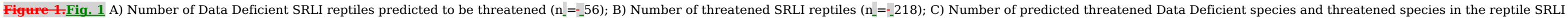
$\left(\mathrm{n}_{-}=--274\right)$. 


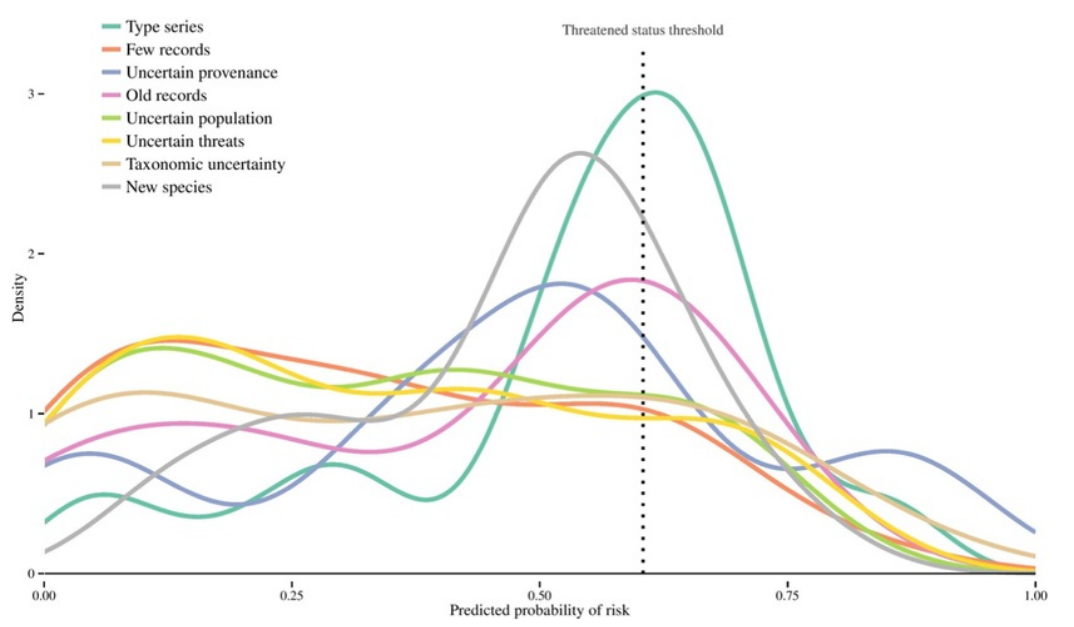

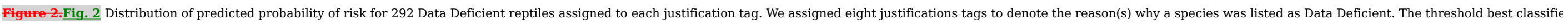
data-sufficient species as threatened or non-threatened based on the predicted probability of risk. Definitions and sample sizes for each justification are available in Appendix A.

\section{alt-text: Fig. 2}

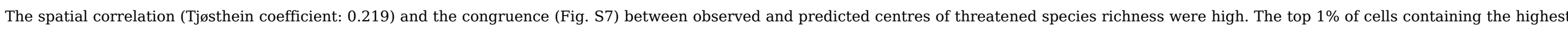

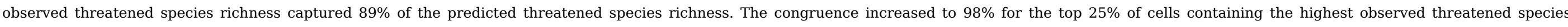

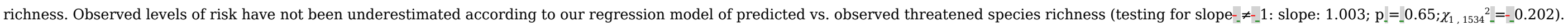

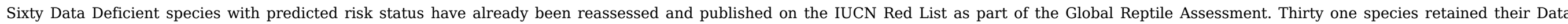

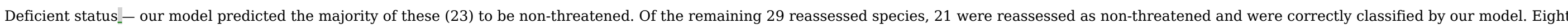

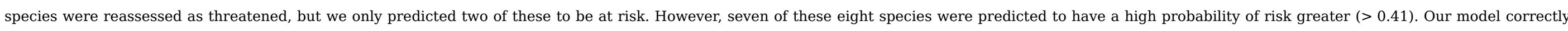
classified 79.3\% of re-assessed Data Deficient species, including 100\% of non-threatened species and 25\% of threatened species

\section{4. $\underline{4}$ Discussion}

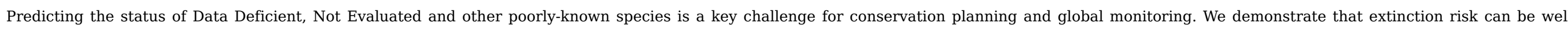

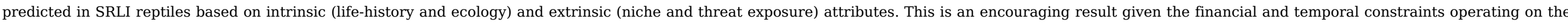

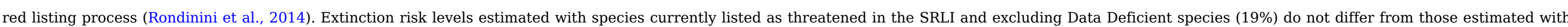

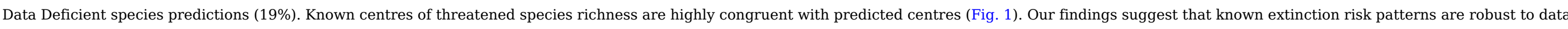
deficiency.

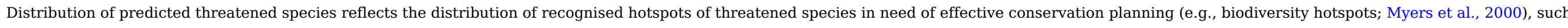

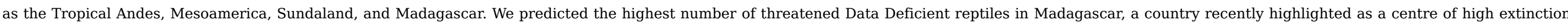

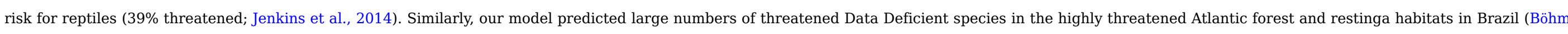
et al., 2013).

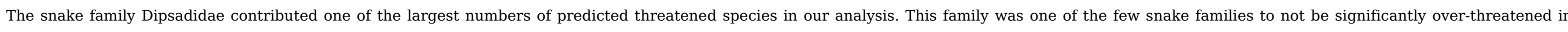

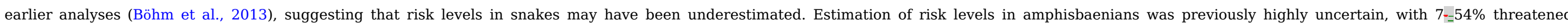

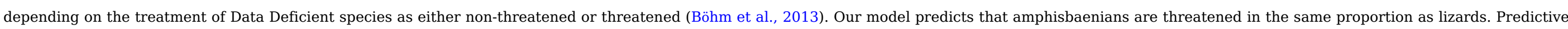




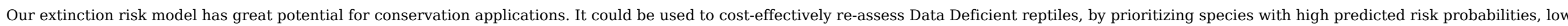

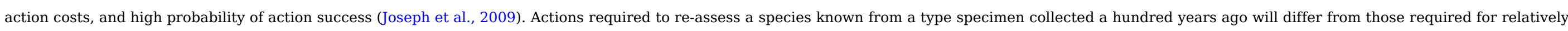

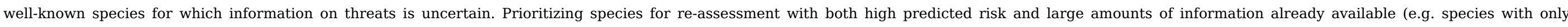

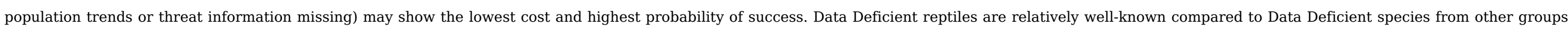
(Bland et al. submitted), so re-assessing reptiles is likely to be less costly, faster, and more successful.

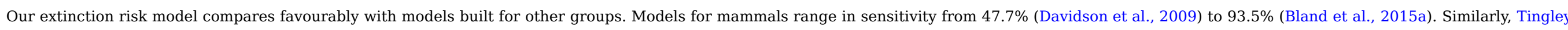

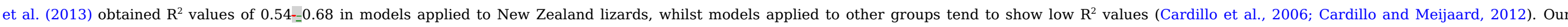

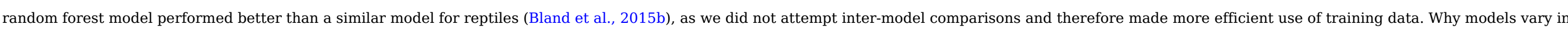

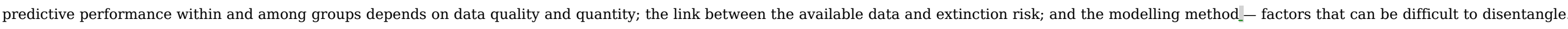

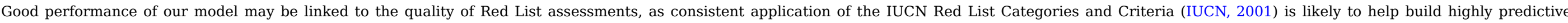

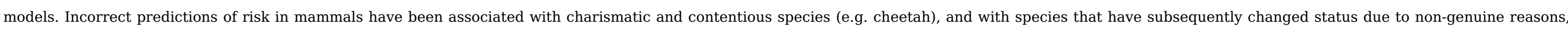

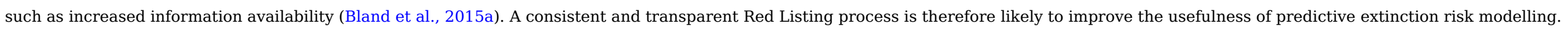

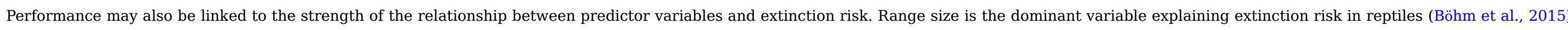

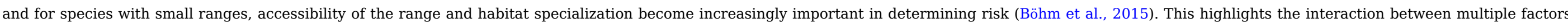

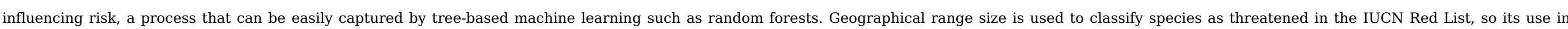

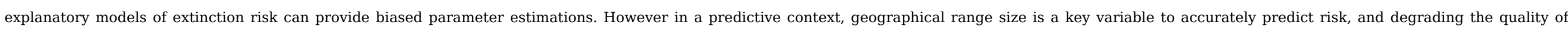
species range maps leads to poor model predictions (Bland et al., 2015b).

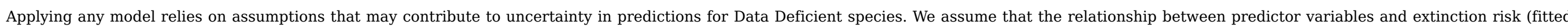

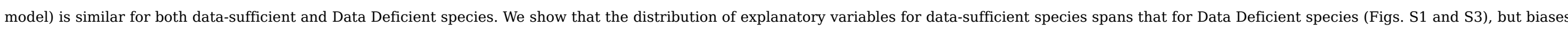
in variable distributions may lead to more uncertain predictions for species possessing traits not well represented in the training set, such as smaller bodies (González-Suárez et al., 2012).

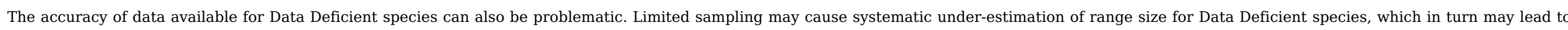

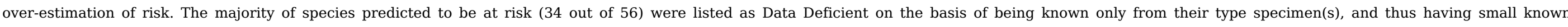

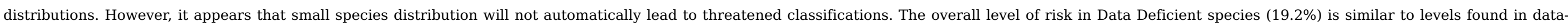

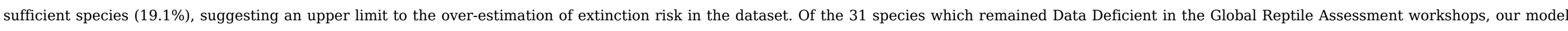
predicted 23 not to be threatened.-_Most of these species (12 out of 23) remained Data Deficient as they were only known from type specimens, few specimens, or the type locality.

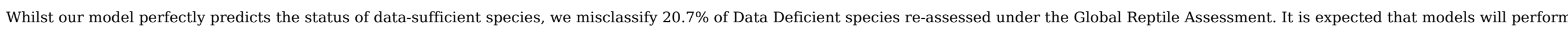

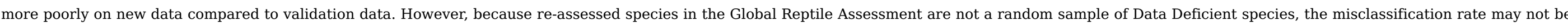

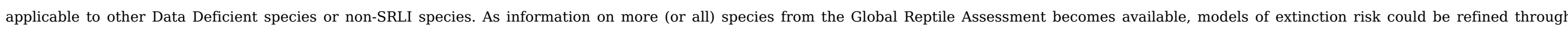

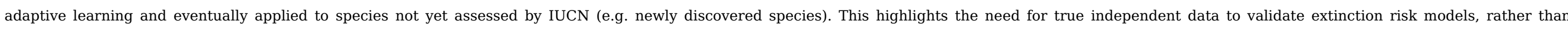

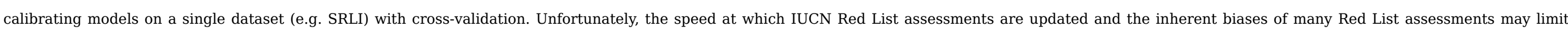
advancements in adaptive learning.

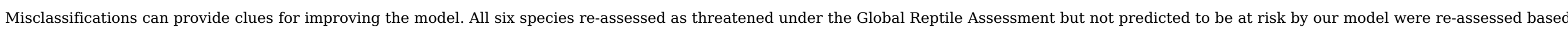

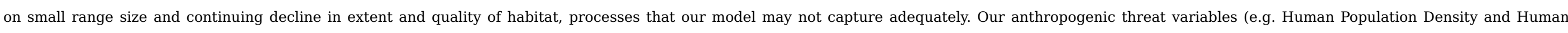

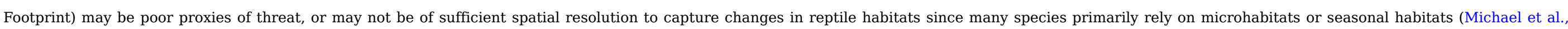

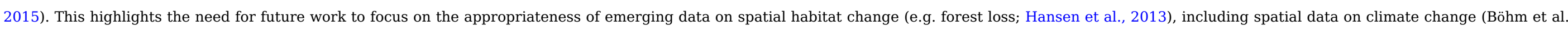




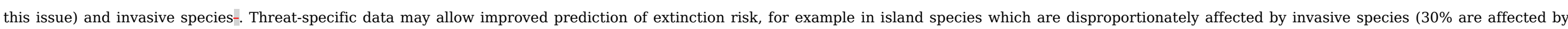
those vs. $12 \%$ on continents). At the same time, there is a need to regularly update existing spatial data layers to allow effective assessment of threats over time (Joppa et al., 2016).

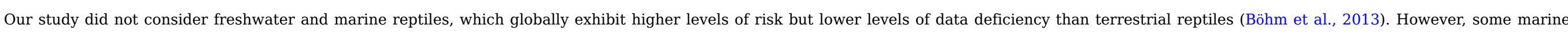

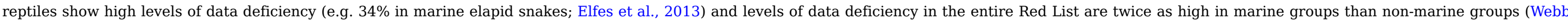

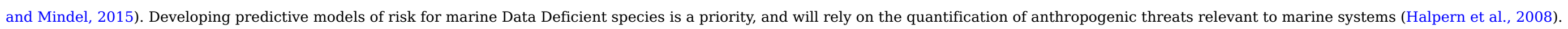

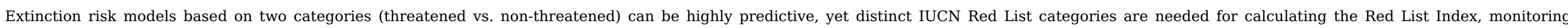

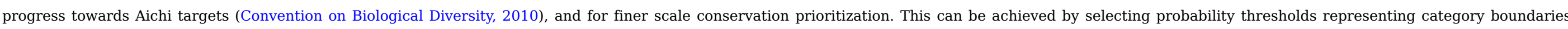

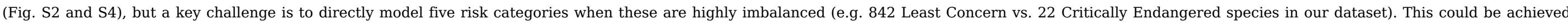
through improved machine learning (e.g. resampling or anomaly detection) or alternative modelling methods (e.g. cumulative link models; Luiz et al., 2016).

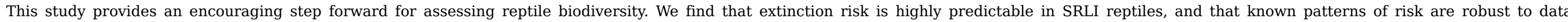

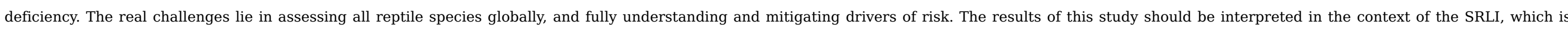

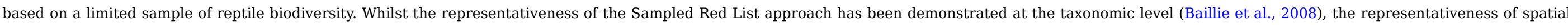

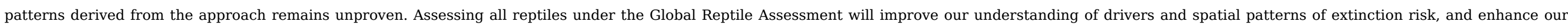
capacity to predict risk across reptile biodiversity.

\section{Acknowledgements}

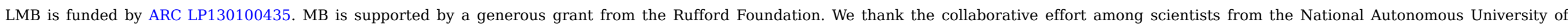
Mexico, Stony Brook University, Nature Serve, and the Institute of Zoology at the Zoological Society of London for the collection of reptile data, particularly Andres Garcia and Ana Davidson.

\section{Appendix A.Appendix A. Supplementary data}

Supplementary data to this article can be found online at http://dx.doi.org/10.1016/j.biocon.2016.05.018.

\section{References}

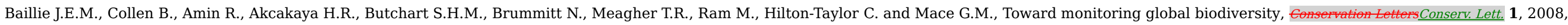
$18-26$.

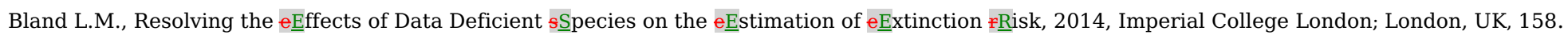

Bland L.M., Collen B., Orme C.D.L. and Bielby J., Data uncertainty and the selectivity of extinction risk in freshwater invertebrates, Điversity and Distributionsivers. Distrib. 18, 2012, 1211-1220.

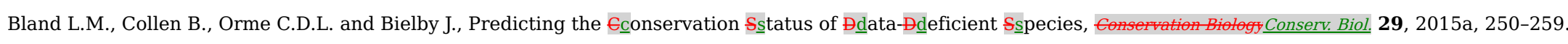

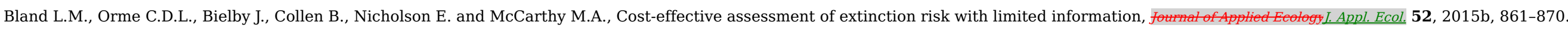

Bland L.M., Bielby J., Kearney S., Orme C.D.L., Watson J.E.M. and Collen B., Towards reassessing Data Deficient species, Conserv. Biol. 2016, (Submitted).

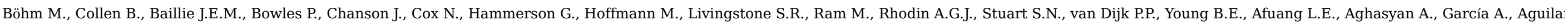

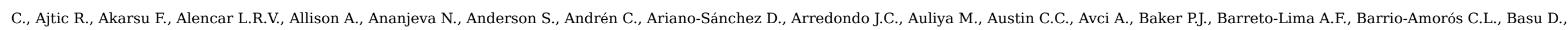

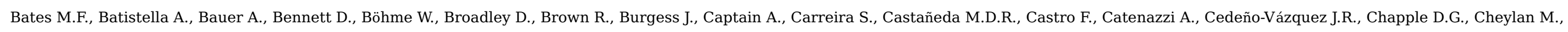

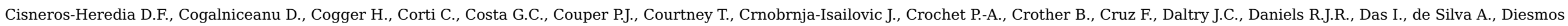

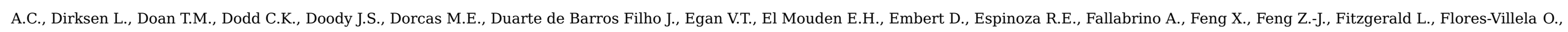

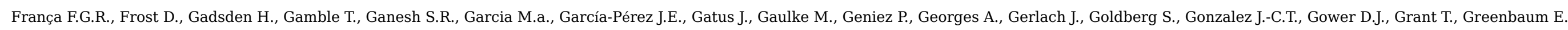




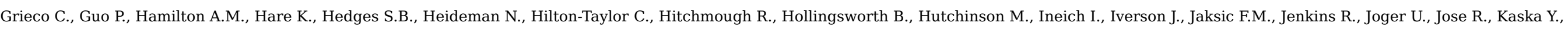

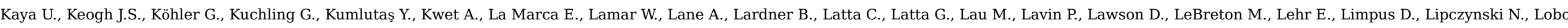

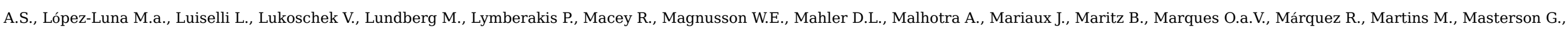

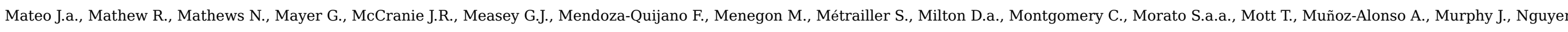

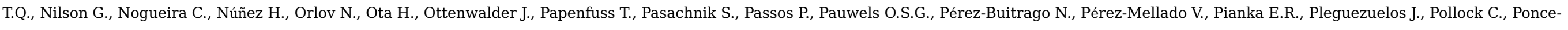

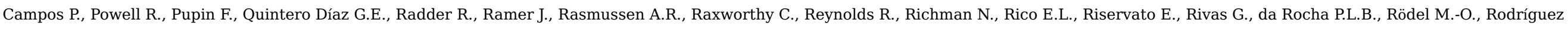

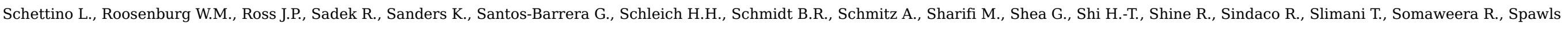

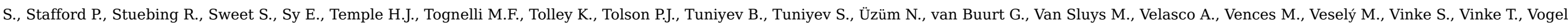

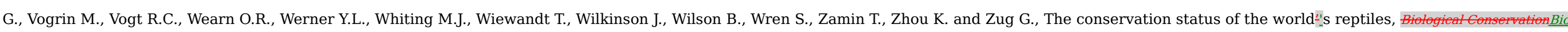
Conserv. 157, 2013, 372-385.

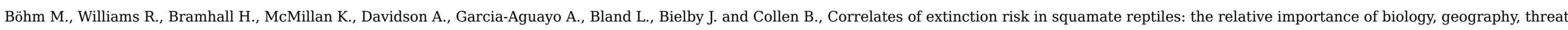
and range size, Global Ecology and Biography Glob. Ecol. Biogeogr. 25, 2015, 391-405.

Breiman L., Random Fforests, 4achime Leaminach. Learn 45, 2001, 5-32.

Breiman L., Manual-Ssetting up, using and understanding random forests v4. 0, http://oz.berkeley.edu/users/breiman.Using random forestsv4.0.pdf 2003.

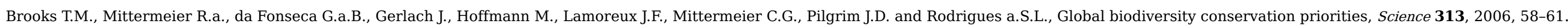
Butchart S.H.M. and Bird J.P., Data Deficient birds on the IUCN Red List: what don't we know and why does it matter?, Biologieal ConservationBiol. Conserv. 143, $2010,239-247$.

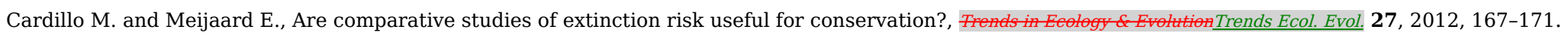

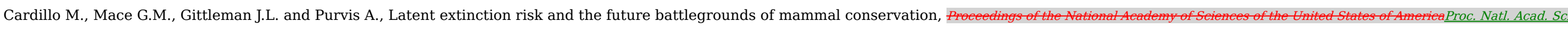
U. S. A. 103, 2006, 4157-4161.

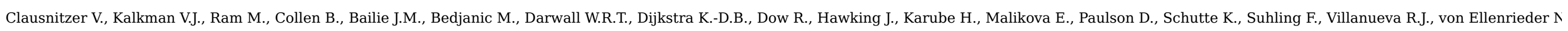

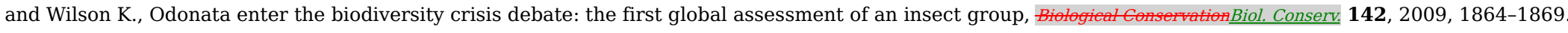

Convention on Biological Diversity, Aichi Targets, Nagoya, Japan, 2010.

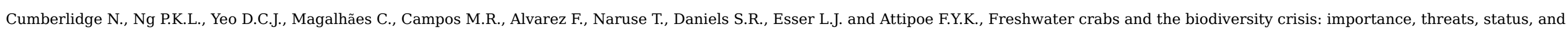
conservation challenges, Biological ConserationBiol. Conserv. 142, 2009, 1665-1673.

Cutler R.D., Edwards T.C., Beard K.H., Cutler A., Hess K.T., Gibson J. and Lawler J.J., Random forests for classification in ecology, Ecology 88, 2007, $2783-2792$.

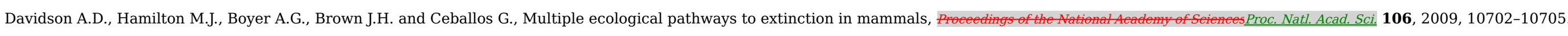

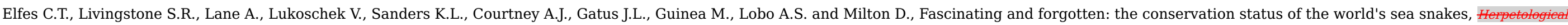
Conseration Biology Herpetol. Conserv. Biol. 8, 2013, 37-52.

Fawcett T., An introduction to ROC analysis, Pattern Recognition LettersPattern Recogn. Lett. 27, 2006, 861-874.

González-Suárez M., Lucas P.M. and Revilla E., Biases in comparative analyses of extinction risk: mind the gap, The Joumal of Animal Ecology I. Anim. Ecol. 81, 2012, 1211-1222.

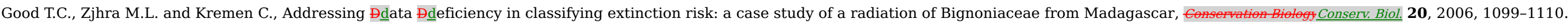

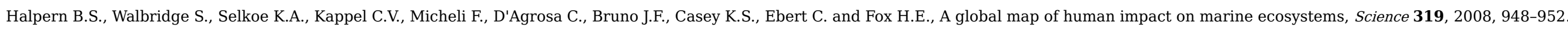




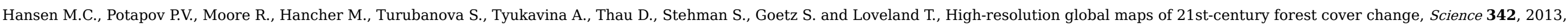
850-853.

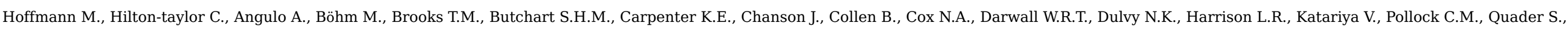

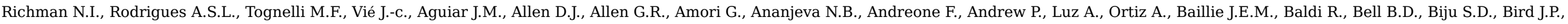

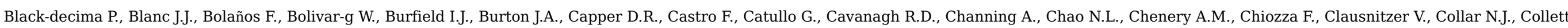

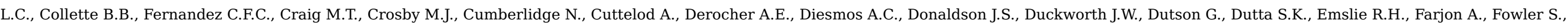

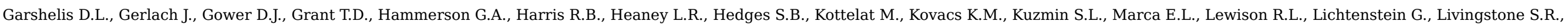

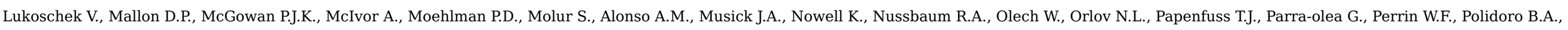

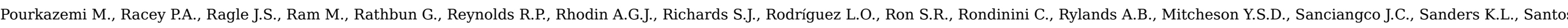

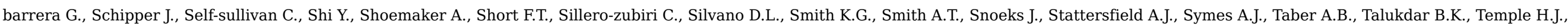

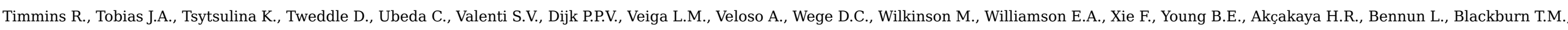

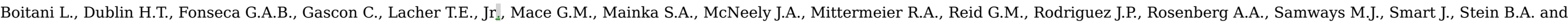

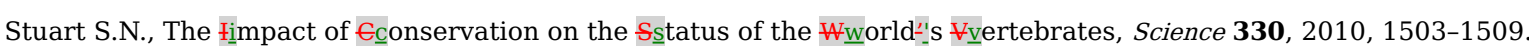

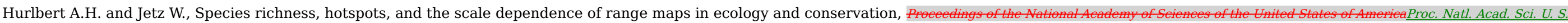
A. 104, 2007, 13384-13389.

IUCN, IUCN Red List Categories and Criteria: $¥ \underline{V}$ ersion 3.1, pp. 30, Gland, Switzerland and Cambridge, UK, 2001.

IUCN, The IUCN Red List of Threatened Species. Version 2015-3, 2015.

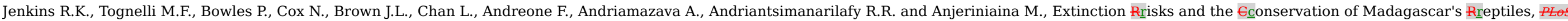
ONEPLOS One $\mathbf{9}$ (8), 2014, e100173.

Jones K.E. and Safi K., Ecology and evolution of mammalian biodiversity, Philos. Trans. R. Soc. B 366, 2011, 2451-2461.

Joppa L., O'Connor B., Visconti P., Smith C., Geldmann J., Hoffmann M., Watson J., Butchart S., Virah-Sawmy M. and Halpern B., Filling in biodiversity threat gaps, Science 352, 2016 , 416-418.

Joseph L.N., Maloney R.F. and Possingham H.P., Optimal allocation of resources among threatened species: a project prioritization protocol, Eenservation Biology Conserv. Biol. 23, 2009, 328-338.

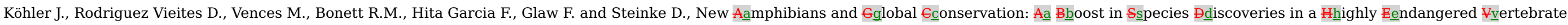
Ggroup, BioseieneeBioscience 55, 2005, 693.

Kuhn M., Building predictive models in R using the caret package, fournal of Statistical Softare]. Stat. Softw. 28, 2008, 1-26.

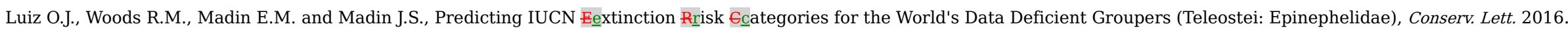

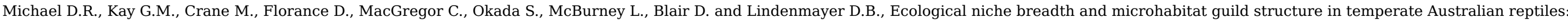

implications for natural resource management in endangered grassy woodland ecosystems, Austral Ecol. 40, 2015, 651-660.

Mohamed bin Zayed Species Conservation, F., The Mohamed Đ̣Bin Zayed Species Conservation Fund, 2014.

Morais A.R., Siqueira M.N., Lemes P., Maciel N.M., De Marco P. and Brito D., Unraveling the conservation status of Data Deficient species, Bielogieal ConservationBiol. Conserv. 166, 2013 , 98-102.

Myers N., Mittermeier R.A., Mittermeier C.G., da Fonseca G.A. and Kent J., Biodiversity hotspots for conservation priorities, Nature 403, 2000 , 853-858.

Prasad A.M., Iverson L.R. and Liaw A., Newer classification and regression tree techniques: bagging and random forests for ecological prediction, Ecosystems $\mathbf{9}$, $2006,181-199$. 


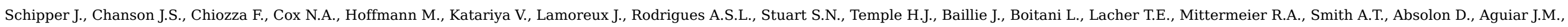

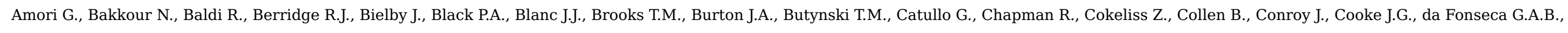

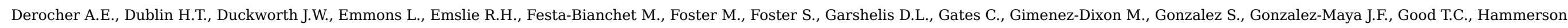

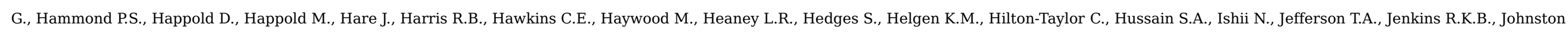

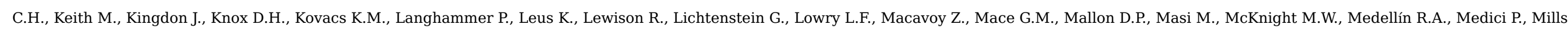

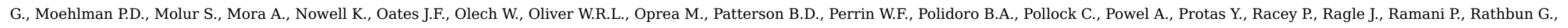

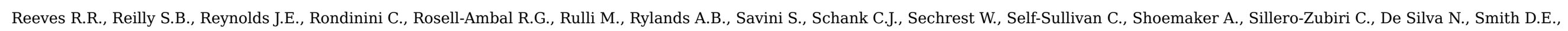

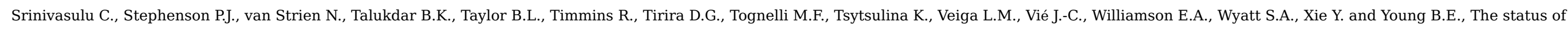
the world's land and marine mammals: diversity, threat, and knowledge, Science 322, 2008, 225-230.

Sousa-Baena M.S., Garcia L.C. and Peterson T.A., Knowledge behind conservation status decisions: data basis for "Data Deficient" Brazilian plant species, Biol. Conserv. 2013.

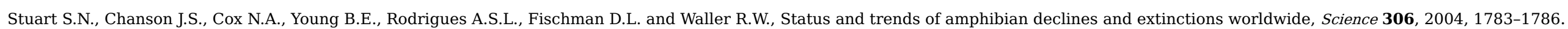

Tingley R., Hitchmough R.A. and Chapple D.G., Life-history traits and extrinsic threats determine extinction risk in New Zealand lizards, Biologieal ConservationBiol. Conserv 165, $2013,62-68$.

Tjøsthein D., A measure of association for spatial variables, Biometrika 65, 1978, 109-114.

Uetz P. and Hošek J., The Reptile Database, 2015.

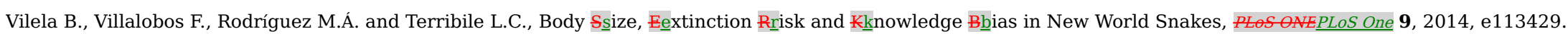

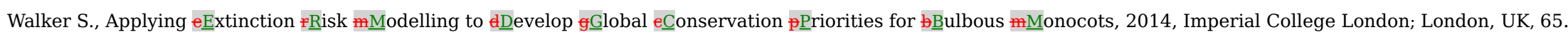

Webb T.J. and Mindel B.L., Global patterns of extinction risk in marine and non-marine systems,

World Association of, Z., Aquaria, World Association of Zoos and Aquaria, 2013.

Youden W.J., An index for rating diagnostic tests, Cancer 3, 1950, 32-35.

\section{Appendix A.Appendix A. Supplementary data}

Multimedia Component 1

Supplementary material 1

alt-text: Image 1

Multimedia Component 2

Supplementary material 2

alt-text: Image 2

\section{Highlights}

- We use random forests to predict the extinction risk of Data Deficient reptiles. 
- We find that $19 \%$ of Data Deficient reptiles are likely to be threatened.

- Global patterns of threatened species richness are robust to data deficiency.

- New information from the Global Reptile Assessment will improve risk models.

\section{Queries and Answers}

Query:

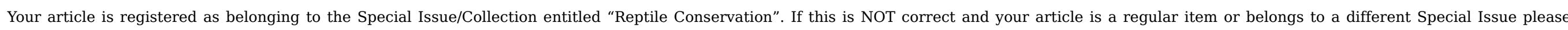
contact v.sethuraman@elsevier.com immediately prior to returning your corrections.

Answer: Yes

Query:

The author names have been tagged as given names and surnames (surnames are highlighted in teal color). Please confirm if they have been identified correctly.

Answer: Yes

Query:

Refs. "Trindade-Filho et al. 2012", "Brito 2010" are cited in text but not provided in the reference list. Please provide it in the reference list or delete the citation from the text.

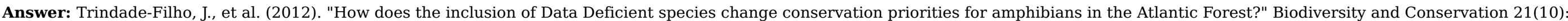
$2709-2718$

Brito, D. (2010). "Overcoming the Linnean shortfall: Data deficiency and biological survey priorities." Basic and Applied Ecology 11(8): 709-713.

Query:

Refs. "Hijmans et al. 2005", “CIESIN 2005a”, "CIESIN 2005b” are cited in text but not provided in the reference list. Please provide it in the reference list or delete the citation from the text. Answer: Hijmans, S. E., et al. (2005). "Very high resolution interpolated climate surfaces for global land areas." International Journal of Climatology 25: 1965-1978.

Ciesin (2005b). Gridded Population of the World (2000), Version 3 (GPWv3). Palisades, NY, Socioeconomic Data and Applications Center (SEDAC), Columbia University.

Ciesin (2005a). Last of the Wild Data Version 2 (LWP-2): Global Human Footprint dataset (HF).

Query:

Supplementary caption was not provided. Please check the suggested data if appropriate, and correct if necessary.

Answer: Appendix A 
Query:

Supplementary caption was not provided. Please check the suggested data if appropriate, and correct if necessary.

Answer: Database on reptile extinction risk in the Sampled Red List Index.

Query:

Please check captured supplementary material "BlandBohm_Data_v5.xlsx" if appropriate. Thank you.

Answer: See inserted file

Query:

Please supply the year of publication.

Answer: This is a submitted manuscript, hence a year of publication is not available. 